\title{
Lógica formal, lógica de contenidos y tiempo en Hegel
}

\author{
IGNACIO FALGUERAS SALINAS \\ Universidad de Málaga
}

Aunque la lógica es tan sólo una parte del sistema hegeliano, es precisamente aquella en la cual tiene su comienzo y a la que, al final, retorna todo él; más aún, el propio método con el que se unifica o traba todo su sistema es también de índole lógica ${ }^{1}$. Para Hegel, incluso el yo y el tiempo, temas de estudio de este congreso, son conceptos -el uno, existente como tal ${ }^{2}$; y el otro, en su completa exterioridad ${ }^{3}-$, pero el concepto, como es bien sabido, constituye el objeto propio de la lógica ${ }^{4}$. Por donde cabe inferir que sólo si se estudia la naturaleza lógica del concepto podrá comprenderse adecuadamente el resto de sus otras manifestaciones. De su parte, la lógica es un saber con una larga historia y muy anterior a Hegel, de manera que, si él ha querido inscribir su metafísica en ese área del saber, ella podrá servir de puente para entender su filosofía. En consonancia con esto, no resultará disparatada la propuesta de investigar lo que une y lo que diferencia a la lógica hegeliana respecto de la lógica al uso o lógica formal ${ }^{5}$, sino, más bien, un modo conveniente de acercarse y de hacer accesible

1 G.W.F. Hegel, Werke in 20 Bänden, Suhrkamp Verlag, Frankfurt a.M., ${ }^{3} 1983$ (HW), 5,$35 ; 6,550$.

2 HW 6, 253; 13, 148.

3 HW 9, 48 ss.

4 “...die tiefere Grundlage ist die Seele für sich, der reine Begriff, der das Innerste der Gegendstände, ihr einfache Lebenspuls, wie selbst des subjektiven Denkens derselben ist. Diese logische Natur, die den Geist beseelt, in ihm treibt und wirkt, zum Bewusstsein zu bringen, dies ist die Aufgabe“ (HW 5,27). „Dieser [der Begriff] wird nicht sinnlich angesschaut oder vorgestellt; er ist nur Gegenstand, Produkt und Inhalt des Denkens und die an und für sich seiende Sache, der Logos, die Vernunft dessen was ist, die Wahrheit dessen, was den Namen der Dinge führt; am wenigsten ist er der Logos, was ausserhalb der logischen wissenschaft gelassen werden soll“" (HW 5, 30).

5 En esa línea inicié una investigación hace más de veinte años con un artículo sobre la formalización lógica de Hegel, Cuatro tesis y una conclusión sobre la formalización lógica de Hegel, Thémata 1(1984) 45-55, que se aclara y continúa en este trabajo. 
a otros el pensamiento de Hegel. Mi objetivo en este trabajo es precisamente ése: servirme de una referencia a la lógica al uso, para introducir y ayudar a entender la lógica de Hegel así como el conjunto de su pensamiento.

A ese fin, consideraré, primero, el papel de la lógica formal en Hegel (I); intentaré, después, destacar lo que distingue a la lógica hegeliana y le permite desarrollar una lógica de contenidos (II); y, tras considerar el tránsito al tiempo y al yo (III), acabaré señalando algunos implícitos básicos de su filosofía que afectan en concreto a la concepción del hombre y de las ultimidades (IV).

\section{LA LÓGICA FORMAL EN HEGEL}

La primera afinidad entre la lógica formal y la lógica hegeliana se encuentra en que ambas se ocupan del saber con un mismo método, es decir, con el método reflexivo, $\mathrm{o}$, lo que es igual, con el uso de la negación. La lógica formal utiliza metódicamente la negación, pero de modo suave, como la mera desconsideración de los contenidos, a fin de atender sólo a las relaciones sincategoremáticas entre las proposiciones o expresiones del pensamiento. Aunque Hegel no podía conocer los desarrollos posteriores de la lógica formal, supo captar en la lógica de su tiempo esa misma idea, que él describe con precisión:

"El concepto de la lógica se asienta hasta ahora sobre la separación, supuesta de una vez por todas en la conciencia ordinaria, del contenido del conocimiento y de la forma del mismo, o de la verdad y de la certeza"6.

La situación de la lógica a la que hace referencia Hegel es la vigente en la filosofía moderna, la cual, según él, contiene tres presupuestos: 1) que la materia del conocimiento existe en sí, fuera del conocimiento, y que el pensamiento se le añade a esa materia como una forma vacía; 2) que entre ambos componentes existe una relación jerárquica según la cual el objeto es perfecto y está acabado, mientras que el pensamiento es imperfecto y ha de amoldarse como forma al objeto; y 3) que, en esta relación, el pensamiento, aunque se hace más determinado, no sale de sí, mientras que el objeto sigue siendo una cosa en sí, y, por tanto, que los dos están aislados ${ }^{7}$.

Hegel señala que esa separación y aislamiento - que reduce el conocimiento a mera subjetividad, y convierte el saber en simple opinión - fueron introducidos por la reflexión moderna, la cual es en sí misma un paso atrás respecto del pensamiento antiguo, para cuya metafísica las cosas son como las pensamos, en el sentido de que lo conocido es la esencia de las cosas mismas. Sin embargo, ese paso atrás es entendido por Hegel como necesario para poder llegar a la

6 HW 5, 36

7 Ibidem, 36-37 
maduración completa de la razón. Sin ese peculiar planteamiento, nos aclara él, no se habría podido notar la necesaria contradicción de las determinaciones del entendimiento, es decir, no habrían surgido las antinomias kantianas, cuya imprescindible aportación consiste, según Hegel, en obligar al pensamiento a una intensificación definitiva de la reflexión. Kant interpretó que las antinomias reflejaban un conflicto o contradicción de la razón consigo misma, y no se dio cuenta de que la contradicción era, más bien, una oportunidad para elevarse por encima de las limitaciones del entendimiento. Por eso, en vez de dar el último paso hacia lo alto, reconociendo que las determinaciones del entendimiento no son satisfactorias, volvió a refugiarse en el conocimiento sensorial para tener algún objeto sólido. Pero como sabía que ese conocimiento no ofrece más que fenómenos o apariencias, admitió su carácter insatisfactorio, culpando a la razón por ello y sometiéndola a crítica ${ }^{8}$. Aún así, Kant tendría el mérito de haber elevado la dialéctica a la categoría de operación necesaria de la razón ${ }^{9}$.

Para Hegel, por tanto, no se trata de abandonar la reflexión lógica moderna, sino de llevarla hasta el final, de manera que si hasta su momento histórico ella sólo (i) había superado la objetividad inmediata, (ii) la había determinado (mediante la negación) y (iii) la había separado de la subjetividad, ahora debería ir más allá de esta determinación separadora y relacionar la objetividad y la subjetividad entre sí. Pero precisamente al intentar relacionarlas es cuando aparece la contradicción, y con ella la razón, pues al poner en relación la segunda reflexión (unificadora de las divisiones) con la primera (superadora de la inmediación objetiva) en la forma de negar lo primeramente separado por la reflexión, ésta última resulta intensificada ${ }^{10}$.

Tal intensificación de la reflexión es lo que le permite convertir la lógica en metafísica o filosofía especulativa ${ }^{11}$, y también lo que más notoriamente diferencia a la lógica hegeliana de la lógica contemporánea. No se equivocan, pues, los lógicos formales cuando clasifican la lógica de Hegel como una lógica metafísica $^{12}$, a la que no saben bien cómo entender, aunque ellos la separen drásticamente de la mera lógica formal.

$8 \quad$ Ibid., 38-41.

9 Ibid., 52.

10 Ibid., 39

11 HW 2, 39; 5, 61.

12 Cfr. Ferrater Mora, "En un sentido estricto, en cambio, solamente merecen el nombre de metafísicas las lógicas para las cuales el correlato de las operaciones lógicas es una realidad metafísica o considerada como tal. Ejemplo de este tipo de lógica es la lógica dialéctica de Hegel y las teorías lógicas desarrolladas por autores más o menos influidos por el hegelianismo, tales como Bradley y Bosanquet" (voz «Lógica», Diccionario de Filosofía, Madrid, 1984, vol. 3 , 2010). 
Para Hegel, la verdad lógica tiene que ser la pura verdad misma ${ }^{13}$, mientras que, como es bien sabido, los lógicos formales distinguen la verdad fáctica respecto de la consistencia o verdad posible, y de la verdad lógica o validez. La reducción de toda verdad a verdad lógica y el desprecio por la verdad fáctica, típicos de Hegel, son para los lógicos formales señal de absolutismo metafísico, y motivo de repulsa generalizada.

Paralelamente, podría pensarse que, al pretender valer como metafísica, la lógica hegeliana debiera hacer con la lógica formal lo mismo que ésta hace con su pensamiento, a saber, desterrarlo. Pero no es así. Ciertamente Hegel critica el formalismo lógico: incoherencia, esterilidad y parcialidad serían los tres defectos que desde su pensamiento se pueden achacar a la lógica formal. Incoherencia, por querer fundar en la experiencia sensible o intuición fenoménica la verdad de los conocimientos racionales. Esterilidad, porque su generalización abstracta no sirve más que para ordenar extrínsecamente los contenidos, obteniendo meras clasificaciones. Parcialidad, porque detenerse en la sola cuantificación de los contenidos, en vez de llegar hasta el final en la generalización, es renunciar a la aspiración más intensa del pensamiento, esto es, al saber total.

Sin embargo, lo meramente formal o insatisfactorio de la lógica no se debe, según él, a que su contenido esté verdaderamente situado fuera de la forma:

"Por el contrario, la carencia de contenido de las formas lógicas radica más bien

sólo en la manera de considerarlas y tratarlas... No es culpa del objeto de la lógica si debe estar carente de contenido, sino sólo del modo como ha sido concebido" ${ }^{14}$.

Cuando, en vez de ser reunidas en una unidad orgánica, las formas son consideradas como determinaciones firmes, inamovibles en su solidez, y, por tanto, desligadas o relacionadas de modo extrínseco entre sí, son formas muertas, en las que ya no reside el espíritu, que es su concreta unidad viviente.

Por lo tanto, las críticas hegelianas descalifican únicamente el uso extrínseco de la reflexión y de la formalidad lógica, mas no afectan al valor de las formas ni de lo formal. A diferencia del planteamiento de Kant y en general del de la Ilustración, Hegel intenta recogerlo e integrarlo todo en su propio pensamiento. Y así afirma rotundamente que la lógica es la ciencia formal, la ciencia de la forma absoluta, que contiene la Idea pura de la verdad misma ${ }^{15}$.

En la medida en que Hegel no descarta la formalidad lógica, sino que la integra en el concepto, se hace necesario distinguir, al menos, dos tipos de

13 WL HW 6, 265

14 HW 5, 41-42.

15 “...daß jene (die Logik) als die formelle Wissenschat nicht auch diejenige Realität enthalten könne und solle, welche der Inhalt weiterer Teile der Philosophie...ist (HW 6, 264) , ...ist die Logik selbst allerdings die formelle Wissenschaft, aber die Wissenschaft der absoluten Form, welche in sich Totalitát ist und die reine Idee der Wahrheit selbst enthalt" (Ibid. 265). 
formalidades en su pensamiento: la formalidad lógica convencional, anterior a su integración en el concepto, y la formalidad lógica integrada: la primera es una formalidad parcial, y por ello falsa, la segunda es la formalidad total, la verdadera.

La formalidad parcial, y sin embargo necesaria, fue descrita ya en sus primeras obras como la consideración aislada en sí de una proposición sin tener en cuenta a su contraria ${ }^{16}$. De ese aislamiento deriva el formalismo, que Hegel ataca porque se hunde en la necesidad empírica ${ }^{17}$ o extramental, y porque se queda corto, al no llegar al contenido ${ }^{18}$. La verdad formal es una verdad abstracta, incompleta, pues la verdad sólo está completa en la unidad de identidad y diferencia ${ }^{19}$. Así

"los dos primeros momentos de la triplicidad son los momentos abstractos, no verdaderos, que justamente por eso son dialécticos" 20 .

Hegel reserva, pues, el sentido kantiano de lo dialéctico, o engañoso, para la verdad formal, es decir, para la formalidad abstracta, o parcialmente verdadera.

Pero también en La Ciencia de la Lógica se habla de una formalidad completamente verdadera, es decir, que suprime la parcialidad de la formalidad dialéctica, pero conserva y eleva lo formal a la generalidad, que es la forma que corresponde al pensamiento puro ${ }^{21}$. De sus textos se infiere: (i) que el método es la generalidad de la forma de todo contenido, o sea, la formalidad general y absoluta $^{22}$; (ii) que es el contenido para sí de la Idea absoluta ${ }^{23}$, así como (iii)

16 HW 2, 230.

17 HW 2, 443.

18 HW 6, 369.

19 HW, 6, 42.

20 HW 6, 566.

21 "In die Logik aber gehören nur die Voraussetzungen des reinen Begriffs, insofern sie die Form von reinen Gedanken, von abstrakten Wesenheiten haben, die Bestimmungen des Seins und Wesens" (HW 6, 470).

22 „Indem die Logik Wissenschaft der absoluten Form ist, so muß dies Formelle, damit es ein Wahres sei, an ihm selbst einen Inhalt haben, welcher seiner Form gemäß sei, und um so mehr, da das logische Formelle die reine Form, also das logische Wahre die reine Wahrheit selbst sein muß. Dieses Formelle muß daher in sich viel reicher an Bestimmungen und Inhalt sowie auch von unendlich größerer Wirksamkeit auf das Konkrete gedacht werden, als es gewöhnlich genommen wird“" (HW 6, 267). "Denn da sie (die Methode) die absolute Form, der sich selbst und alles als Begriff wissende Begriff ist, so ist kein Inhalt, der ihr gegenüberträte und sie zur einseitigen, äußerlichen Form bestimmte" (HW 6, 568).

23 "Die logische Idee hat somit sich als die unendliche Form zu ihrem Inhalte ... Die absolute Idee selbst hat näher nur dies zu ihrem Inhalt, daß die Formbestimmung ihre eigene vollendete Totalität, der reine Begriff ist. Die Bestimmtheit der Idee und der ganze Verlauf dieser Bestimmtheit nun hat den Gegenstand der logischen Wissenschaft ausgemacht, aus welchem 
que la forma de su determinación es la totalidad completa. En consecuencia, ha de decirse que en Hegel existe una formalidad no parcial, sino total y verdadera, que es el fundamento absoluto y la verdad última ${ }^{24}$. Por supuesto que esto se cumple sobre todo al final, pero no exclusivamente en el último momento de la lógica, sino a lo largo de todo su desarrollo, pues para Hegel la forma es la verdad de todo contenido determinado ${ }^{25}$.

En este sentido, escribía:

"Sin embargo, tal como acabo de hacer notar, obviamente la razón lógica, cuando es considerada como razón formal, ha de ser reconocida esencialmente también en la razón que tiene que ver con contenidos; mejor aún, todo contenido puede ser racional sólo por medio de la forma racional"26.

Esa vigencia de lo formal incluso en el contenido racional es lo que autoriza a pensar que también la lógica formal puede ayudar a entender mejor a Hegel. No se trata en absoluto de intentar reducir el método de Hegel a mera lógica formal, sino de comprender cómo se puede conservar en él hasta el final una dimensión lógico-formal ${ }^{27}$.

Para aclarar el sentido de tal integración de la formalidad enuncio las tres siguientes proposiciones:

1. La lógica de Hegel contiene una esencial e imprescindible dimensión formal que se encuentra ya en el comienzo absoluto mismo, en cuanto que éste es la generalidad vacía o absolutamente indeterminada. En efecto, el comienzo o inmediación pura es el elemento del pensar, es decir, aquello en lo cual se mueve el pensamiento y gracias a lo cual existe con anterioridad a todo contenido determinado, razón por la que no necesita admitir ningún presupuesto ${ }^{28}$.

Verlauf die absolute Idee selbst für sich hervorgegangen ist; für sich aber hat sie sich als dies gezeigt, daß die Bestimmtheit nicht die Gestalt eines Inhalts hat, sondern schlechthin als Form, $\mathrm{da} ß$ die Idee hiernach als die schlechthin allgemeine Idee ist. Was also hier noch zu betrachten kommt, ist somit nicht ein Inhalt als solcher, sondern das Allgemeine seiner Form, - d. i. die Methode." (HW 6, 550).

24 “...und statt daß ein gegebenes Objekt die Grundlage sein könnte, zu der sich die absolute Form nur als äußerliche und zufällige Bestimmung verhielte, hat sich diese vielmehr als die absolute Grundlage und letzte Wahrheit erwiesen" HW 6, 551.

25 “...insofern sie (die Form) die Seele aller Objetivität ist und aller sonst bestimmte Inhalt seine Wahrheit allein in der Form hat" (HW 6, 551).

26 "Es muss aber, wie soeben bemerk worden, offenbar die logische Vernunft, wenn sie als die formelle betracht wird, wesentlich auch in der Vernunft, die es mit einem Inhalte zu tun hat, zu erkennen sein; ja vielmehr kann aller Inhalt nur durch die vernünftige Form vernünftig sein" (HW 6, 352).

27 Eso era lo que pretendía establecer la proposición tercera del escrito mío antes referido: no que el Principio de De Morgan agote el método hegeliano, pero sí que tenga cierta vigencia incluso en el tercer momento metódico.

28 HW 5, 72-73. Sin embargo, existe un presupuesto: la negatividad o poder del pensar, 
Pero ese comienzo ha de ser intrínseco al pensamiento, de manera que ha de poder ser reconocido por el pensar en el pensar mismo. El único modo de que el comienzo sea inmanente a la lógica, es decir, quede comprendido en y por el pensamiento, es dejar de lado toda otra consideración y aceptar sólo lo que está presente ${ }^{29}$. Pues bien, ese comienzo o inmediación es, para el pensar, la generalidad sin contenido alguno, por eso dice de él:

"porque el comienzo como comienzo del pensar debe ser enteramente abstracto, enteramente general, enteramente forma sin ningún contenido"30.

Es, así, una nada de contenido, y, a la vez, el ser como generalidad máxima o totalmente abstracta, o sea, la formalidad pura del pensar separada de todo contenido.

2. El comienzo formal puro no forma parte del proceso, no se mueve, sino que es su base constante e inalterable. De él dice Hegel lo siguiente:

"Así, el comienzo de la filosofía es el fundamento presente y que se conserva en todos los desarrollos siguientes, lo que permanece inmanente a través de todas sus ulteriores determinaciones" 31 .

Tanto es así que al final del proceso lógico, el comienzo puro es aquella unidad a la que vuelve el saber lógico, o si se quiere considerar como ha de estar al principio -es decir, mantenerlo aún como forma distinta de su unidad-, aquel ser puro que, ahora sí, constituye su contenido. Los textos nos cercioran, pues, de que el comienzo hegeliano, que no forma parte del proceso, lo acompaña sin sufrir alteración alguna.

Pero esto ocasiona un problema, ya que la lógica hegeliana es una lógica procesual, en movimiento, ¿cómo puede acompañar el comienzo a una lógica que avanza, y que debería dejarlo atrás?, ¿cómo puede mantenerse inmutable el comienzo en todos los desarrollos sucesivos? Precisamente en este punto puede ayudarnos un principio lógico-formal, el Principio de De Morgan o del Complemento. Dicho principio enuncia que la suma de A y de No-A da lugar a una verdad necesaria $(A \cup \bar{A}=\mathrm{I})$, pues forma un universo de discurso, o lo que es igual, una generalidad extensionalmente máxima: en la unión de A y de No-A queda aludido todo, de modo que no cabe tener una extensión mayor, y siempre

incluida en la condición antinómica de todo lo pensado y de todo lo real.

29 " $\mathrm{Da}$ nun von dieser Bestimmung des reinen Wissens aus Anfang seiner Wissenschaft immanent bleibe, ist nichts zu tun, als das zu betrachten oder vielmehr mit Beiseitsetzung aller Reflexionen, aller Meinungen, die man sonst hat, aufzunehmen, was vorhanden ist" (HW 5, 68). Para Hegel el núcleo esencial del tiempo es la eternidad, el presente (o presencia mental), que lo niega en su finitud.

30 “... weil der Anfang, als des Denkens, ganz abstrakt, ganz allgemein, ganz Form ohne allen Inhalt sein soll" (HW 5, 73).

31 HW 5,71. 
ha de corresponderle algún caso particular que la valide de hecho. Ahora bien, como la síntesis - o tercer momento del proceso hegeliano - reúne a los dos primeros, que son contradictorios entre sí, puede ser asemejada - siempre que se deje de lado la consideración meramente fáctica - a la suma de A y de No-A, lo cual daría lugar a que todas y cada una de las síntesis dialécticas fueran universos de discurso, es decir, a que todas fueran máximamente extensas, $\mathrm{y}$, por consiguiente, a que todas sean iguales en cuanto a su extensión. De este modo se comprendería cómo se conserva inalterado el comienzo (o generalidad máxima) a lo largo del proceso dialéctico, pues todas las síntesis serían tan generales como el propio comienzo, aunque más determinadas en su contenido que él ${ }^{32}$.

3. Merced a esa igualación, el proceso lógico no se desarrolla tanto en sentido extensional como en sentido intensional ${ }^{33}$, y camina no desde una generalización menos extensa a otra más extensa, sino de una generalización menos comprehensiva a otra más comprehensiva. La extensionalidad del concepto permanece alcanzada e inalterada desde el comienzo absoluto, y se mantiene desde la primera síntesis hasta la última, mientras que las comprehensividades van creciendo. Se produce, en la intención de Hegel, un trueque de la lógica extensional por la intensional, no porque deje de existir lo extensional, sino porque alcanza su máximo en el mismo inicio y lo mantiene inalterado a lo largo de todas las síntesis, de manera que la atención mental pasa a considerar, en vez de la dimensión lógico-formal o extensional, el contenido concreto de cada síntesis ${ }^{34}$. En virtud, pues, de la extensión máxima de todas las síntesis,

32 Naturalmente, al diferenciarse entre sí por su determinación, los universos de discursos que resultan son diferentes entre sí, y, en consecuencia, pueden ser considerados como unos máximos relativos. Esto permite pensar a Hegel que, siendo siempre máxima su extensión, las síntesis sólo puedan ser «mayores» unas respecto de otras por el aumento de sus intensiones o comprehensiones.

33 Hegel conoce la distinción entre lo extensivo y lo intensivo, cfr HW 3, 208; 5, 250$260 ; 6,419 ; 570$. "Aber es ist nun auch erfülltes Sein, der sich begreifende Begriff, das Sein als die konkrete, ebenso schlechthin intensive Totalität" (HW 6, 572).

34 En HW 3, 208 se dice que la intensión real es tan grande como la extensión, y viceversa, de manera que lo orgánico puede crecer a la vez en intensidad y en extensión, sin que en cada caso el aumento de la una haya de significar la disminución de la otra. Esto podría parecer que contradice a mi propuesta de aumento de la intensión manteniéndose igual la extensión. Sin embargo, el texto intenta más bien señalar que la necesidad de que el aumento de intensidad vaya acompañado de una disminución de la extensión, y viceversa, nace de una oposición vacía, o sea, de una representación hecha sin concepto. Para Hegel, el proceso real lleva consigo un aumento simultáneo de la intensión y de la extensión, por tanto su pensamiento no admite el principio lógico de que a mayor extensión, menor comprensión, ni viceversa. En realidad, lo que vengo sugiriendo es que, en Hegel, cada síntesis consigue una extensión máxima y una comprensión relativamente máxima. Para entender esto que digo es conveniente tener en cuenta el siguiente texto: "Auf diese Weise ist es, dass jeder Schritt des Fortgangs in Weiterbestimmen, indem er 
la lógica de Hegel puede pretender ser una lógica que se ocupa de los contenidos. Sin lo negable (generalidad vacía) no podría existir la negación primera, pero la negación primera no suprime lo negable, sino que admite ser sumada a él, cosa que hace la segunda negación hegeliana ${ }^{35}$. Al reunir lo negable y su negación, por un lado se alcanza la máxima extensión, y, por otro, lo formal negativo genera el contenido pensado, convirtiéndose en un medio para la intensificación del pensar.

Evidentemente, no sostengo que Hegel conociera el principio lógicoformal de De Morgan, pero sí que en cada uno de los terceros momentos de su proceso dialéctico captó y utilizó lo que ese principio enuncia. Dicho de otro modo, como la lógica de Hegel sigue siendo lógica, o pensamiento reflexivo, la neutralización de las diferencias extensionales de los conceptos mediante el efecto «De Morgan», implícito en la doble negación, le permite concentrar toda su atención en aquello de los conceptos que los lógicos considerarían su dimensión semántica, aunque entendida no como una semántica meramente lingüística, sino del modo especial que explico a continuación.

\section{LA LÓGICA DE CONTENIDOS}

Una vez expuesta la permanencia de lo formal hasta el final de la lógica hegeliana, conviene atender a lo más característico de ésta, que es, sin duda, su pretensión de constituir una semántica peculiar, a saber, una semántica generada por la forma o por el método. De este modo, cabrá descubrir más fácilmente lo que añade Hegel a la lógica meramente formal.

El punto de partida de la peculiaridad del pensamiento hegeliano es su modo de entender las antinomias kantianas. Un gran mérito de Kant, nos dice, consiste en haber elevado la dialéctica desde la condición de acto arbitrario, tal como comúnmente se la consideraba, a la de una acción necesaria de la

vom dem unbestimmten Anfang sich entfernt, auch eine Rückannäherung zu demselben ist, dass somit das, was zunächst als verschieden erscheinen mag, das rückwärtsgehende Begründen des Anfangs und das vorwärtsgehende Weiterbestimmen desselben, ineinanderfällt und dasselbe ist" (HW 6, 570). Nótese que, en el texto, lo que progresa es la determinación, mientras que el comienzo es aquello a lo que se retorna. Para que pueda cerrarse un círculo, que es la traza de su método, es preciso que el punto de partida se mantenga inalterado; si variara, ya no podría retornarse a él. Y, para que el retorno sea cabal, es preciso que conserve durante todo el trayecto la misma curvatura que tenía en su inicio. Cada paso adelante en la determinación sólo será una vuelta hacia su comienzo si mantiene la generalidad máxima de su arranque. La extensión es máxima en el comienzo; la intensificación o determinación se aleja de la indeterminación máxima del comienzo, pero al incrementarse se va aproximando a lo absoluto o máximo del comienzo, hasta que al final la intensión es tan absolutamente máxima como la extensión, que ya lo era desde el principio.

35 Esto lo ha explicado magistralmente mi maestro, L. Polo, en Hegel y el posthegelianismo, Eunsa, Pamplona, ${ }^{2} 1999,61$ ss. 
razón ${ }^{36}$; eso no obstante, Kant se quedó corto tanto en su valoración como en su propuesta de las antinomias. Lo propio de Hegel estriba en montar todo su pensamiento sobre «la» antinomia de la razón. Ya en sus primeros escritos afirma rotundamente que la ley más alta de la lógica son las antinomias ${ }^{37}$. Y en la Enciclopedia nos repite que este pensamiento de que la contradicción es esencial y necesaria constituye uno de los más importantes y profundos progresos de la filosofía moderna ${ }^{38}$, pero añade lo siguiente:

"lo más importante que ha de ser destacado es que la antinomia no sólo se encuentra en los cuatro objetos especiales tomados de la Cosmología, sino, lo que es más, en todos los objetos de todas las especies, en todas las representaciones, conceptos e ideas" 39 .

Hegel parte, pues, del presupuesto de que todo pensamiento es esencial y necesariamente antinómico, y esta propiedad es la base del momento dialéctico de lo lógico ${ }^{40}$. Por tanto, Hegel generaliza las antinomias a todo el pensamiento, de ahí que en vez de hablar en plural, se refiera a ellas en singular como una sola antinomia que hace dialéctica a la razón ${ }^{41}$. Kant propuso cuatro contradicciones, pero son pocas, pues las antinomias, afirma Hegel, están por todas partes ${ }^{42}$.

Pero veámoslas más de cerca. Las antinomias son pares de proposiciones opuestas que, refiriéndose al mismo objeto, se contradicen y que, sin embargo, han de ser afirmadas de él a la vez y con la misma necesidad ${ }^{43}$. Kant quedó paralizado por ellas, y retrocedió horrorizado ante la experiencia de estar pensando sin pensar ningún objeto ${ }^{44}$. En vez de quedar paralizado y retroceder como Kant por tales antítesis inconciliables, Hegel las tomó como punto de partida para su pensamiento, pues él sostiene que la contradicción puede ser pensada, y que, en vez de paralizar el pensamiento, viene a ser su verdadero principio motor $^{45}$. Según Hegel, todas las antinomias descansan sobre el pensamiento formal, en la medida en que mantienen y afirman los dos momentos de la idea separados, cada uno para sí, y, por ello, en su no verdad e inadecuados a la

36 HW 5, 52.

37 HW 2, 123.

$38 \S 48, \mathrm{HW} 8,126$.

$39 \S 48$, HW 8, 127-128.

40 Ibid.

41 HW 20, 356.

42 Ibid:: "allenthalben".

43 HW 8, 126.

44 I. Falgueras, Perplejidad y filosofía trascendental en Kant, Cuadernos de Anuario Filosófico, Servicio de Publicaciones de la Universidad de Navarra, Pamplona, 1999, 46.

45 La contradicción está en la raíz de todo movimiento y vitalidad (HW 6, 75). "In der Tat aber ist das Denken des Widerspruchs das wesentliche Moment des Begriffes" (HW 6, 563). 
idea ${ }^{46}$. Esta alusión a la formalidad nos permite caer en la cuenta del parecido y de la diferencia entre el modo de pensar la contradicción por el Principio de De Morgan y por Hegel. En efecto, el Principio de De Morgan piensa la contradicción yuxtaponiendo los contradictorios y sólo para sacar una consecuencia extensional, la de la máxima amplitud o generalidad de ese enunciado, ya que aun cuando uno de los contradictorios haya de ser falso, la verdad del otro hace necesario el valor positivo final de su suma. Hegel, en cambio, considera a los dos contradictorios como falsos en su mera parcialidad o separación, pero, en vez de eliminar a uno u otro de ellos, los conserva a ambos para mantener aquella máxima amplitud formal, así como la determinación que la negación lleva consigo, y elimina únicamente su separación, reuniéndolos por el lado de los contenidos. Pero para entender adecuadamente esta ampliación del principio de De Morgan es preciso todavía tener en cuenta las indicaciones siguientes.

1. La lógica de Hegel es una lógica que se pretende construida sin una especial atención a los sincategoremas, pues se apoya únicamente en el operador negación. Pero el operador negación es - como dicen los lógicos formales - un operador monádico, o sea, que no enlaza proposiciones ni contenidos, sino que ha de recaer directamente sobre algún contenido. Para que la negación pueda ser la única formalidad constructiva en la lógica de Hegel es preciso, como se acaba de ver, que todo contenido posible esté intrínsecamente afectado por ella, es decir, sea constitutivamente antinómico. Por eso, a la lógica de Hegel sólo le pueden resultar aplicables principios lógicos como el del Complemento (o de De Morgan), que contiene y aprovecha la negación contradictoria.

2. Hegel sostiene que, en vez de retroceder ante la contradicción, es preciso mantener firme la mirada en los contradictorios, en los dos a la vez y conjuntamente, sin optar por uno u otro, sino atendiendo a la unidad que les confiere el ser mutuamente contradictorios ${ }^{47}$. Para ello ha de recordarse que la antinomia, $\mathrm{o}$ contradicción que se toma como punto de partida, contiene una relación mutua de los contradictorios, de manera que, según Hegel, no se puede entender un contradictorio sin el otro, antes bien, precisamente por ser contradictorios, si se pone uno, el otro queda afectado ${ }^{48}$. Al mantener la atención de la razón en

46 "Diese Antinomie beruht, wie alle Antinomie, auf dem formellen Denken, das die beiden Momente einer Idee getrennt, jedes für sich, damit der Idee nicht angemessen und in seiner Unwahrheit, festhält und behauptet" (HW 7, 123).

47 "Das spekulative Denken besteht nur darin, daß das Denken den Widerspruch und in ihm sich selbst festhält, nicht aber, daß es sich, wie es dem Vorstellen geht, von ihm beherrschen und durch ihn sich seine Bestimmungen nur in andere oder in nichts auflösen läßt” (HW 6, 76). "...aber das Spekulative ist, diesen Gegensatz vor sich zu haben und ihn aufzulösen" (HW 20, 429).

48 HW 6, 252; cfr. Ibid. 294: „Ihre (des Begriffes) Bestimmungen sind nicht so ein Totliegendes wie Zahlen und Linien, denen ihre Beziehung nicht selbst angehört; sie sind lebendige 
los contradictorios, Hegel no niega por completo el principio de contradicción, lo que niega es que la contradicción elimine al pensamiento, pues él sostiene, muy por el contrario, que le sirve de alimento y lo fortalece, es decir, que el pensamiento la puede asimilar.

La lógica formal, una vez establecido el principio de De Morgan, se queda en la mera afirmación de que la suma de dos contradictorios tiene siempre una correspondencia de casos verdaderos fuera del pensamiento, es decir, se queda en la verdad fáctica. Hegel, en cambio, se da cuenta de que la contradicción de los contradictorios es pensada, y por tanto, de que el pensamiento no es suprimido por la contradicción, antes bien se puede seguir pensando los dos contradictorios a la vez y, entonces, se alcanza precisamente la máxima altura del pensamiento, lo que él llama la especulación ${ }^{49}$. Mientras que el dogmatismo toma un contradictorio como verdadero y otro como falso, o sea, unilateralmente, el idealismo de la filosofía especulativa los reúne, pues posee el principio de la totalidad ${ }^{50}$. La lucha de la razón consiste en sobrepasar aquello que el entendimiento ha fijado ${ }^{51}$.

Pero prestemos más atención a lo que se entiende por «especulativo». La relación mutua de los contradictorios antinómicos hace que, cuando en vez de retirar la mirada se mira a uno de ellos, en él aparezca el otro, y viceversa. En el fondo esto tiene cierta semejanza con lo que había descubierto Espinosa, y que podría resumirse así: Natura naturans sive Natura naturata. Es decir, cuando miro a Dios me aparece el mundo (Natura) sólo que al modo de la causa, o como «naturante»; cuando miro al mundo, me aparece Dios (Natura), pero al modo de los efectos, o como «naturado». De modo similar acontece en Schelling, quien lo expresaba con esta otra fórmula: A=B. A no es B, y B no es $\mathrm{A}$, pero como su igualdad los hace equivalentes, cuando se mira a «A», entonces aparece «B», aunque bajo el matiz de «A»; y cuando miro a «B», entonces me aparece «A», pero con el matiz de «B»; de manera que ambos forman la unidad en movimiento (o potencial) de dos distintos, la naturaleza

Bewegungen; die unterschiedene Bestimmheit der einen Seite ist unmittelbar auch der anderen innerlich; was bei Zahlen und Linien ein volkommener Widerspruch wäre, ist der Natur des Begriffes wesentlich". (El destacar es mío).

49 „Das Wahrhafte, das Spekulative ist dagegen gerade dieses, welches keine solche einseitige Bestimmung an sich hat und dadurch nicht erschöpft wird, sondern als Totalität diejenigen Bestimmungen in sich vereinigt enthält, welche dem Dogmatismus in ihrer Trennung als ein Festes und Wahres gelten" (HW 8, 99).

50 „Der Dogmatismus der Verstandesmetaphysik besteht darin, einseitige Gedankenbestimmungen in ihrer Isolierung festzuhalten, wohingegen der Idealismus der spekulativen Philosophie das Prinzip der Totalität hat und sich als übergreifend über die Einseitigkeit der abstrakten Verstandesbestimmungen erweist" (Ibid.).

51 „Der Kampf der Vernunft besteht darin, dasjenige, was der Verstand fixiert hat, zu überwinden“ (Ibid.) 
(A) y el espíritu (B). Si A y B son equivalentes, lo que les diferencia es sólo cierta preponderancia en el modo en que se muestran, aunque su contenido sea el mismo. Por su parte, en Hegel acontece que cuando se atiende a «A» aparece que su contenido es «no-A», y cuando se atiende a «no-A» se cae en la cuenta de que su contenido es «A». Este remitir del uno al otro de los contradictorios lleva a tener que pensarlos a los dos en movimiento recíproco, y sugiere entenderlo como movimiento circular ${ }^{52}$. Para Hegel, la consideración conjunta de los dos contenidos contradictorios es más que lo que sugiere el Principio de De Morgan, o sea, no es una mera suma extensional o simple yuxtaposición de los contradictorios, tampoco es un producto (imposible) entre ellos, sino una suma intensional, entendida no estática, sino dinámicamente, de tal manera que los dos contradictorios, aunque no tengan como tales ningún territorio común, integran un movimiento continuo en la unidad más intensivamente general de un nuevo concepto.

3. Pues bien, cuando se ha mantenido la mirada fija en la contradicción mutua, sin que nosotros hagamos nada, como pura iniciativa de la unidad de los contradictorios, sobreviene lo imprevisto, lo concreto, el contenido ${ }^{53}$. Entonces parece que los contradictorios mismos se unen en un movimiento rotativo mutuo y nos conducen a una ampliación del pensar. La clave de esta ampliación radica en la doble negación. Hegel distingue la negación simple, o en general, y la negación doble o negación de la negación ${ }^{54}$. Las negaciones usuales son las simples, que establecen un límite o determinación. Con las negaciones simples se puede separar, pero no se puede construir nada, porque son operadores monádicos, que no sirven para enlazar. Pero cuando los contenidos son concebidos como intrínsecamente antinómicos, o sea, como negaciones mutuas, la negación pasa a convertirse en doble negación, y, por su mutua respectividad, en medio de unión de los contenidos contradictorios. En este sentido, la negación de la negación es la negatividad absoluta ${ }^{55}$, el enorme poder del negativo ${ }^{56}$, que es un momento de la naturaleza divina ${ }^{57}$, aquel en el que lo finito es absorbido en lo infinito.

52 La negación mutua es lo que tienen en común los contradictorios, es su unidad, por lo que los otros contenidos que les pertenecen se vienen a sumar, pero no siendo compatibles directamente entre sí, la suma es sólo la continuidad del uno por el otro, o sea, el movimiento del pensar que vuelve sobre sí.

53 "Sondern es kann nur die Natur des Inhalts sein, welche sich in wissenschaftlichen Erkennen bewegt, indem zugleich diese eigene Reflexion des Inhalts es ist, welche seine Bestimmung selbst erst setzt und erzeugt" (HW 5, 16).

54 HW 5, 124.

55 HW 10, 214.

56 HW 3, 36.

57 HW 17, 295. La reflexión es momento positivo del absoluto (HW 3, 25). 
Para entender esto último es preciso tener en cuenta lo siguiente. Como la doble negación está contenida en los propios contradictorios mutuos, no es algo que sea puesto por la subjetividad del que piensa, sino que pertenece a lo pensado. Son los contradictorios pensados los que vuelven sobre sí, puesto que cada uno remite al otro como a su esencia, por lo que, al mantener la mirada en ellos es lo pensado lo que se pone en movimiento a sí mismo y mueve al pensamiento. Lo «divino» y «milagroso» es, para Hegel, que lo pensado cobre vida por sí mismo, se ponga en movimiento y haga pensar lo que ha de pensarse. Lo mismo que el artista cuando se siente inspirado es movido a y por la producción de la belleza, sin que se atribuya a sí mismo la grandeza de su obra de arte, porque ha sido movido y guiado a ella, así Hegel atribuye a lo pensado -no a su propia habilidad-, el movimiento y la vida del pensamiento. Todo lo que ha de hacer el hombre es no arredrarse ante la contradicción, sino soportar el horror y la división o muerte del entendimiento, para dejar que ella desenvuelva su propia vida racional por sí misma. En consecuencia, lo pensado dialéctica o contradictoriamente genera nuevos pensados, o dicho con otras palabras, para Hegel lo pensado piensa ${ }^{58}$.

Pero, además, la negación de la negación contenida en los contradictorios no puede ser, como en la lógica extensional, una afirmación simple, o sea, una mera eliminación de la negación con simple retorno a lo afirmativo (No «no $\mathrm{A} »=\langle\mathrm{A} »)$, sino una afirmación nueva, una afirmación infinita ${ }^{59}$ : infinita porque es máximamente general, es decir, lo abarca todo (efecto «De Morgan»), pero afirmación porque es una noción general concreta, no abstracta. El gozne sobre el que pivota la transformación milagrosa o divina que, según Hegel, produce la negación de la negación es que ella es una afirmación como vuelta sobre $s i^{60}$. A esta vuelta sobre sí se debe la supervivencia del pensar más allá de la contradicción. Con la expresión «vuelta sobre sí» se indica la actividad reflexiva. Hegel sabe que toda negación es una reflexión, por lo que entiende que la negación de la negación habrá de ser la reflexión perfecta y completa. Si

$58 \mathrm{Y}$, naturalmente, si lo pensado piensa, el pensar es pensado. En la interpretación del nous aristotélico Hegel deja claro su propio convencimiento: "Da also das Gedachte und der vou 5 nicht verschieden sind, als welche keine hyle haben, sind sie dasselbe; und es ist nur ein Gedanke des Gedachten" (HW 19, 166). Que en eso esté de acuerdo con Aristóteles lo demuestra el texto final de la Enciclopedia, en cuya traducción alemana se vierte "oste tautòn nous kaì noetón" por "so daß Vernunft und Gedachtes dasselbe ist" (HW 10, 394).

59 HW 10, 214; 16, 179.

60 La negación de la negación es afirmación como vuelta sobre sí mismo (HW 5, 160). La negación de la negación es lo que vuelve sobre sí mismo (HW 16, 423). Por tanto, el contenido del contenido es la formalidad reflexiva. Es ésta forma la que genera el contenido, la formalidad verdadera. Pero, antes, lo antinómico del contenido (la forma falsa) ha generado la forma verdadera. 
la negación simple determina la generalidad limitándola-como supo descubrir, aunque no aprovechar, Espinosa ${ }^{61}-$, la doble negación suprime la limitación mutua y conserva a los opuestos (generalidad y determinación) en la forma de una generalidad infinita y concreta. En efecto, como la negación simple recae siempre sobre una afirmación general previa, determinándola ${ }^{62}$-esto es, suprimiendo la vigencia ilimitada de su generalidad-, cuando recae sobre sí misma tiene un resultado doble, pues por ser negación suprimirá lo negativo de la primera negación, pero por ser negación de la negación convergerá hacia la negatividad misma ${ }^{63}$. En este sentido, la doble negación se muestra como una marcha atrás que suprime y conserva: tiene el valor de una reflexión que retiene conjuntamente la generalidad y la determinación sin su separación, por lo que no sólo sugiere un nuevo contenido, sino que contiene la guía de su movimiento, a saber, la vuelta sobre sí. El núcleo motor del contenido es, en última instancia, la reflexividad del negativo, es decir, una operación formal.

Una vez entendido que la negación de la negación es una vuelta sobre sí o reflexión completa, la cuestión pertinente en este momento sería ¿qué es lo que vuelve sobre sí mismo, o cuál es el «sí» sobre el que se vuelve? Lo que vuelve sobre sí mismo es la negatividad de los contradictorios, de manera que ellos son lo pensado, pero su contradictoriedad es el pensar sobre el que se vuelve. Por consiguiente, los contradictorios no sólo piensan, sino que se piensan. En definitiva, para Hegel lo pensado piensa y se piensa a sí mismo ${ }^{64}$.

La lógica de contenidos no es, por tanto, una lógica elaborada por el hombre, sino que es la lógica que se desprende de los contenidos mismos, es decir, de lo pensado. El sujeto en Hegel no es el yo, sino el concepto, lo pensado que piensa y se piensa. Y el sujeto absoluto es la Idea, es decir, el concepto que reúne la intensión y la extensión absolutamente máximas. Por su parte, los contenidos mismos son sólo diversos grados de intensidad en el ejercicio de la reflexión o negatividad, que quedan todos integrados en el grado máximo, el Absoluto, pero no son, en modo alguno, aleatorios o cualesquiera (substituibles por variables), sino necesaria y precisamente los que piensa (y nos sugiere) el concepto según su orden.

61 HW 20, 164.

62 La reflexión determinante es el estar puesto como negación (HW 6, 33).

63 La supresión (Aufhebung) de lo negativo de sí mismo es la convergencia (Zusammengehen) consigo (HW 6, 27).

64 Sin estas aclaraciones no se entendería bien el juego hegeliano entre lo «en sí» y lo «para sí», que perfila los detalles del movimiento dialéctico. Ni lo «en sí» ni lo «para sí» hacen referencia al sujeto individual pensante (Hegel, o el filósofo), sino a lo pensado pensante. 


\section{EL TIEMPO EN HEGEL}

Después de alcanzada la Idea absoluta se inicia, según Hegel, un nuevo proceso, cuya principal virtud reside en que saca a la luz la importancia de la forma y del contenido lógicos en su filosofía. Sin duda, la mayor de las muchas sorpresas que depara su pensamiento es la de que la Idea Absoluta, la racionalidad perfecta, se enajena libremente, se despoja de su racionalidad ${ }^{65}$. Sin embargo, al pensamiento, que ha partido de un comienzo absoluto, se ha construido a sí mismo a lo largo de un proceso necesario, y ha llegado a identificar en sí lo pensado y el pensarse, no le puede quedar nada por pensar, ni tiene sentido que deje de pensar, ¿cómo es, pues, que comienza de nuevo?

$\mathrm{Al}$ respecto, Schelling señaló con acierto:

"Ahora bien, no se puede comprender, de ninguna manera, qué debió mover a la Idea -después de que ella se elevó al sujeto más alto y absorbió completamente el ser- a desubjetivarse de nuevo, a rebajarse a la condición de mero ser, y a dejarse desmoronar en la mala exterioridad del espacio y del tiempo"66.

Hegel no replicó, que yo sepa, a esa crítica de Schelling -que, por lo demás, no fue publicada, sino sólo repetida en sus clases-, pero cabría colegir una respuesta a partir de lo que expuso en la Enciclopedia. Ciertamente, como sugiere también Schelling, la razón de la alienación debería contenerse en la propia Idea absoluta, no en razones extrínsecas, que para ella (sujeto-objeto absoluto) no pueden existir. Al decir esto, Schelling piensa que, no habiendo razón alguna para la alienación, el verdadero motivo de la misma es sólo salir de la esfera del mero pensar y buscar contenidos reales para el sistema, que no puede reducirse - si quiere se completo- a la mera lógica. Por mi parte, sin embargo, intentaré buscar la posible razón hegeliana de la alienación en aquello que acontece con ella y puede resultar significativo para la Idea.

Si concentramos la atención en la Idea absoluta, lo único que le puede quedar por hacer, tras haber alcanzado su plenitud racional, es despojarse de ella, o sea, alienarse. La alienación es, obviamente, una auto-negación de la Idea absoluta ${ }^{67}$. Y lo que la alienación niega en la Idea es precisamente lo

65 Aunque al final de La Ciencia de la Lógica se habla sólo de tránsito (Übergang), en la Enciclopedia, al inicio de la Filosofía de la Naturaleza, se hace abundante referencia a la «alienación» (Entfremdung) de la Idea.

66 Zur Geschichte der neueren Philosophie, herausg. von M. Schröter, Münchner Jubiläumsdruck, 5, 224, trad. esp. L. de Santiago, Málaga, 1993, 244.

67 La naturaleza es la Idea en la forma del ser otro (Anderssein), es decir, lo negativo de sí misma (HW 9, 24), su negación puesta, y la caída (Abfall) de la Idea (Ibid. 27-28). La naturaleza es, así, la Idea en su inmediatez y exterioridad o sea la muerte (Ibid. 36). La naturaleza es el Hijo de Dios (Cristo), pero no como Hijo, sino como permanencia (de la Idea) en el ser otro; es el espíritu alienado (Ibid.25). 
último que la Idea se ha procurado, a saber, la vuelta al comienzo absoluto. El pensar y el ser se identifican en la Idea, pero ésta rompe voluntaria y libremente tal identidad, negando su propia unidad con el comienzo (ser y elemento del pensar). De este modo, se introduce un nuevo comienzo, pero que esta vez está precedido por la auto-negación de la Idea ${ }^{68}$.

Pues si prestamos atención al conjunto, lo que con la alienación se introduce es un proceso por el que la Idea, alcanzada su plenitud, se permite hacer alarde del poder absoluto de la negatividad que en ella reside y que la ha generado. En La Ciencia de la Lógica, la negación aparecía en segundo lugar, era lo que inmediatamente seguía al comienzo absoluto. Pero ahora, al abandonar el ser o comienzo, lo que queda en la Idea es ya solamente el poder de negar, sólo que esta vez dicho poder no aparece como segundo, puesto que es él mismo el que se separa de la identidad de pensar y ser, y de la generalidad del comienzo ${ }^{69}$. Se muestra, en consecuencia, cómo la Idea absoluta puede negar su propio elemento, o sea, su punto de partida y el medio en que se desenvuelve, sin sucumbir por eso. Ella no se niega por completo a sí misma, sino sólo la forma de la generalidad en la que reposa la naturaleza lógica del pensar ${ }^{70}$. Lo cual refrenda claramente la propuesta hecha desde el principio en este trabajo: la formalidad general, común a la lógica usual y a Hegel, es un componente esencial de su lógica, el elemento de la racionalidad, por lo que, cuando es abandonada por la Idea, ésta se sale de la racionalidad.

Para Hegel, no se trata, pues, de que haya quedado algo sin pensar, algún terreno inexplorado para el pensamiento, sino más bien de que el poder del pensar no ha sido mostrado en todas sus posibilidades, no ya en cuanto a las determinaciones racionales, sino en su propia negatividad. Entre las dos dimensiones del pensamiento, el contenido y la forma, ha servido de mediación el poder del negativo o la intensidad reflexiva máxima del concepto. Nada ha quedado sin desarrollar en La Ciencia de la Lógica, ni la objetividad ni la subjetividad ni su unión, pero el poder mediador del concepto no ha sido exhibido en su total plenitud. La alienación de la Idea va a servir para mostrar lo que Hegel piensa que es lo más radical de todo, el poder transmutador del negativo,

68 El gran problema que surge aquí es el siguiente: si pierde su plenitud, la Idea deja de ser Idea, abandona su eternidad, pero eso es imposible, pues lo eterno no puede -por definición- dejar de serlo. Hegel parece enfocarlo de modo semejante a como lo hace el hinduismo con Visnú: la Idea sólo se reviste de formas o disfraces externos, pero conserva su naturaleza divina, el poder del negativo.

$69 \mathrm{Al}$ hacerlo, pierde el efecto propio del principio de De Morgan: la generalidad máxima o universo de discurso.

70 Esto obliga a distinguir netamente en el contenido lo que hay de determinado y lo que hay de formal, lo determinado o finito es variable, mientras que, por su parte, lo formal es constante, o sea, el verdadero contenido del contenido: la negatividad auto-reflexiva. 
que le permitirá resurgir, como el ave fénix, de sus cenizas ${ }^{71}$.

Así pues, la locura de la Idea es fruto de la suficiencia de su poder, y consiste en abandonar la generalidad absoluta del pensamiento ${ }^{72}$. Aunque Hegel advierte que el comienzo de la lógica es absoluto, $\mathrm{y}$, por tanto, primero $-\mathrm{o}$ que no parte de ningún presupuesto-, entiende que el negativo tiene tal poder que, aun siendo segundo respecto de la formalidad general del comienzo absoluto, es capaz de suscitar (al final) su propio elemento, la logicidad. La Idea absoluta se puede incluso negar a sí misma, alienándose, es decir, negando su generalidad máxima y su sujeto-objetivación perfecta, con tal de que conserve el poder de negar, que es la verdadera consistencia del concepto. En el fondo, como digo, si, una vez llegado a plenitud, el concepto se niega a sí mismo, se despoja de su formalidad y de su objetividad máximas, sólo parece que habría de ser para mostrar cuál es, en verdad, su verdadera esencia y poder: la negación de la negación.

Siendo la formalidad racional lo que se abandona y el núcleo del contenido (o negatividad) lo que se conserva en la alienación, el proceso que sigue a ésta no es otra cosa que una seriación de las distintas figuraciones que el poder del negativo va asumiendo fuera de la generalidad lógica, o sea, en la particularidad ilógica, hasta reconstruir su propio elemento.

En ese proceso, tras el comienzo en el mundo de lo irracional y aleatorio, el tiempo es la primera figuración de que se reviste el poder del negativo, que es el que va configurando la Filosofía de la Naturaleza. En cambio, el yo, o espíritu finito, es la primera vuelta sobre sí en el tiempo por parte del poder del negativo, su primera forma de existencia verdadera fuera de la lógica. Tal recuperación de la reflexividad del concepto pone en movimiento a la Filosofía del Espíritu, y se despliega desde la conciencia subjetiva hasta aquella objetivación de la reflexividad en el tiempo que llega a formar el Espíritu de los

71 "So ist das Bild des Phönix bekannt; es ist aus dem Morgenlande überhaupt gekommen. So finden wir bei den Alten Gedanken über Leben und Sterben, Übergang des Seins ins Vergehen: aus Leben komme Tod, aus Tod Leben; im Sein, Positiven sei selbst schon das Negative enthalten. Das Negative soll ebenso selbst schon in sich das Positive enthalten; alle Veränderung, Prozess der Lebendigkeit bestehe darin“ (HW 18, 111). ,Diese Entfremdung, dieses Anderssein , als natürliche Negation bestimmt, ist der Tod, aber der Tod, der ebenso aufgehoben wird, indem daraus ein verjüngtes Aufleben eintritt“" (HW 16, 408).

72 Al afirmar esto no excluyo que tenga su parte de razón Schelling, que atribuye la alienación a la necesidad de ofrecer un sistema completo del saber humano, el cual no puede quedarse en la sola lógica, sólo muestro una posible justificación intrasistemática de la alienación. Y, desde luego, no por proponerla, sugiero que sea posible eludir las muchas y decisivas objeciones que se opondrían a esa justificación. Entre ellas destaco que todo tipo de exhibición se hace ante terceros (que no pueden existir según Hegel), no para sí mismo, a no ser que se esté inmaduro o acomplejado, y en ambos casos se haría porque se necesitaría aclarar ese poder por no haber sido suficientemente aclarado (cosa inadmisible desde La Ciencia de la Lógica). 
pueblos, o sea, la historia universal. Pero la recuperación de la logicidad, o sea, de la formalidad de la Idea, perdida en la alienación, no se obtiene hasta que el poder del negativo, identificado consigo mismo, no se separa por completo del tiempo, cosa que acontece en tres pasos, a saber, en el arte, la religión y la filosofía. En la filosofía, el Espíritu se eleva a su puro principio, la generalidad, suprimiendo toda contingencia temporal y recobrando el elemento puro que había abandonado la Idea, con lo que retorna a su propia naturaleza lógica y racional.

\section{El RESULTADO FINAL.}

La generalización de la contradicción descrita páginas atrás es sólo el planteamiento radical del que parte Hegel, pero no es su última palabra. Hegel pretende resolver la contradicción general. En este sentido, no deroga el principio de contradicción, sino que lo cumple justamente cuando la resuelve. El final, lo más alto, no es el problema, sino la solución:

"llevar hasta el final el proceso de oposición, contradicción y solución de la contradicción es el más alto privilegio de las naturalezas vivas" $" 73$.

La solución de la contradicción está contenida en la Idea ${ }^{74}$, es decir, en la región de la verdad en sí misma ${ }^{75}$, en el concepto, al que no llega el entendimiento $^{76}$, y es obtenida mediante la doble negación. Éste es el terreno de la lógica. Pero el poder de la negatividad sobrepasa lo meramente lógico, se adueña de la Idea y la incita a alienarse, a ponerse fuera de su elemento, o sea, fuera de la formalidad. Así queda clara la importancia de lo lógico-formal, puesto que, cuando se abandona o pierde, se pierde también la racionalidad. Con todo, el concepto, constituido nuclearmente por el poder del negativo, no sucumbe a la pérdida de la racionalidad, sino que inicia un nuevo proceso para la recuperación de la formalidad lógica, cuyo motor será, primero, la negatividad constitutiva del tiempo y, más tarde, la negatividad del yo o espíritu finito, el cual elevándose hasta el espíritu de los pueblos y a través del arte, la religiosidad y la filosofía, acabará precisamente en la recuperación de la eternidad propia de la Idea en su elemento lógico. De manera que también por este cabo se advierte la importancia de la formalidad lógica, puesto que el final de todos los procesos adviene cuando se recupera la formalidad perdida en la alienación, que, desde luego, no será ya una formalidad parcial o extrínseca, sino la formalidad total absoluta.

Ahora bien, si antes del final absoluto todo está en movimiento relativo,

73 HW 13, 134.

74 HW 17, 225.

75 HW 13, 137: La verdad es la solución de la más alta contradicción.

76 HW 17, 230. 
¿cómo se transforma la relatividad de lo móvil en absolutez definitiva? Si ha sido en todo momento el poder del negativo el que ha impulsado los distintos procesos en el sistema de Hegel, incluida la alienación de la Idea, entonces ¿qué otro poder cabe que lo detenga? ¿Cómo puede una última contradicción resolver todas las contradicciones? O dicho de otro modo: ¿cómo puede la negación doble convertirse en simple afirmación?, ¿cómo puede el poder del negativo anularse a sí mismo, convertirse de negatividad pura en positividad absoluta?

Todos sabemos que en lógica formal la doble negación afirma, pero lo hace porque no es una negación mutua, sino que la segunda tan sólo neutraliza el efecto de la primera operación de negar. En el caso de Hegel la cosa no es tan sencilla. Como los contradictorios son mutuos, la doble negación no es un mero operador extrínseco que pueda ponerse, quitarse o neutralizarse, sino que caracteriza intrínsecamente a los opuestos. ¿Cómo, pues, lo entiende Hegel?

Como ya se vio, Hegel distingue entre la negación simple y la doble. La negación simple o abstracta es un tránsito que se da en el concepto ${ }^{77}$, mientras que la negación doble es la solución de las antinomias y la determinación fundamental de la filosofía. Esta última tiene como característica el constar de dos resultados simultáneos: elevar y suprimir, conservar y eliminar ${ }^{78}$. Aunque el efecto, como digo, es doble, en ella cabe resaltar, especulativamente, tanto el aspecto conservador como el de supresión.

Si consideramos, primero, ese doble efecto conservador-supresor, pero poniendo el énfasis en la elevación conservadora, no deberá extrañarnos que Hegel encuentre como símil más cercano para la doble negación la actividad nutritiva orgánica ${ }^{79}$, pues la principal efectividad del organismo es superar sus propias producciones y expulsarlas ${ }^{80}$. La nutrición, dice, es el momento mediador de la vida, el que ejecuta la vuelta a sí (reflexiva) del viviente. Naturalmente,

77 HW 11,545

78 HW 5, 113-114; 3, 94; 8, 204.

79 La negatividad del tiempo es interpretada por Hegel según el mito de Cronos, que devora a todos sus hijos (HW 9, 49). El pensar es también comparado con el comer: "das Essen wird freilich in diesem Verhältnisse als undankbar vorgestellt, denn es ist das Verzehren desjenigen, dem es sich selbst verdanken soll. Das Denken ist in diesem Sinne nicht weniger undankbar" (HW 8, 57); y lo mismo el saber (HW 8, 43). "Die Befriedigung des Hungers ist Aufheben der Trennung zwischen mir und meinem Objekt, ist Aufheben der Endlichkeit, jedoch nur formelles" (HW 16, 175).

$80, \ldots$... die Hauptwirkung des Organismus, seine eigenen Produktionen zu überwinden und wegzuschaffen" (HW 9, 482). "Diese Verkehrung der Ansicht ist das Prinzip der Reflexion des Organismus in sich; die Rückkehr in sich ist die Negation seiner nach außen gerichteten Tätigkeit. Sie hat die doppelte Bestimmung, daß er seine mit der Äußerlichkeit des Objekts in Konflikt gesetzte Tätigkeit von sich einerseits exzerniert, andererseits, als unmittelbar identisch mit dieser Tätigkeit für sich geworden, in diesem Mittel sich reproduziert hat“(Ibid. 480-481). 
el símil nos sugiere cómo entiende Hegel la actividad reflexiva del pensar ${ }^{81}$ : pensar es asimilar, o sea, aprovechar los contradictorios, introduciéndolos en el concepto y expulsando lo que no se acomoda a él.

Otro símil de la doble negación reflexiva que utiliza Hegel es el de la muerte. La interpreta como un momento necesario de la vida, como un tránsito imprescindible, y como el momento mediador por el que la vida vuelve a sí misma. Para él, la muerte es el destino del individuo finito, es la negación abstracta de la vida, o lo que es igual, la dimensión de la negación que elimina o suprime lo sobrante, el individuo ${ }^{82}$. Pero en realidad, ésa es sólo su función inmediata, ya que sin la contradicción que aporta la muerte, no cabría volver a la vida. Por eso, dice que la contradicción (o muerte) es la raíz de la vida ${ }^{83}$ o el momento del nacimiento de una vida más alta, la del espíritu ${ }^{84}$. Todo lo que es pasa o muere, pero el pasar también pasa ${ }^{85}$. En consonancia con eso, Hegel piensa que la vida absoluta o divina contiene la muerte como momento inmanente suyo ${ }^{86}$, ya que si no hay muerte, no hay resurrección. La vida completa

81 La verdad es la mediación de sí mismo a través de la negación del otro (HW 17, 466).

82 „So in feindlichem Verhalten andere zur unorganischen Natur herabsetzend, ist der gewaltsame Tod das natürliche Schicksal der Individuen“ (HW 9, 500). La muerte, negación natural abstracta o simple de la singularidad acaba el proceso de formación del individuo (HW 11, 535). "Im Tode ist das Endliche als aufgehobenes gesetzt. Aber der Tod ist nur die abstrakte Negation des an sich Negativen; er ist selbst ein Nichtiges, die offenbare Nichtigkeit. Aber die gesetzte Nichtigkeit ist zugleich die aufgehobene und die Rückkehr zum Positiven. Hier tritt das Aufhören, das Loskommen von der Endlichkeit ein. Dies Loskommen von der Endlichkeit ist im Bewußtsein nicht das, was der Tod ist, sondern dies Höhere ist im Denken, - schon in der Vorstellung, soweit darin das Denken tätig ist" (HW 16, 175-176).

83 HW 6, 75, 76 y 481. „Die absolute Form, der Begriff und die Lebendigkeit hat vielmehr allein die qualitative, sich an sich selbst aufhebende Differenz, die Dialektik der absoluten Entgegensetzung, zu ihrer Seele. Insofern diese wahrhafte unendliche Negativität nicht erkannt ist, kann man meinen, die absolute Identität des Lebens, wie bei Spinoza die Attribute und Modi in einem äußeren Verstand vorkommen, nicht festhalten zu können, ohne den Unterschied zu einem bloß Äußerlichen der Reflexion zu machen; womit es dem Leben an dem springenden Punkt der Selbstheit, dem Prinzipe der Selbstbewegung, Diremtion seiner selbst in sich überhaupt fehlt" (HW 9, 470).

84 "Denn der Tod hat eine gedoppelte Bedeutung: einmal ist er das selbst unmittelbare Vergehen des Natürlichen, das andere Mal der Tod des nur Natürlichen und dadurch die Geburt eines Höheren, des Geistigen, welchem das bloß Natürliche in der Weise abstirbt, daß der Geist dies Moment als zu seinem Wesen gehörig an sich selbst hat" (HW 13, 451).

85 HW 16, 316: „Was ist, das vergeht. Der Tod ist aber ebensosehr wieder der Anfang des Lebens; das Vergehen ist der Anfang des Entstehens und es ist nur Umschlagen vom Sein in das Nichtsein, und umgekehrt.... ; aber sie ist wieder die Macht des Vergehens, so daß das Vergehen vergeht".

$86, \ldots$,..denn der Tod wird dem Göttlichen immanent, und der Gott stirbt... Das Negative ist hier auch nur das Natürliche, aber als Tod des Gottes nicht nur das Beschränkte eines Bestimm- 
resulta ser, así, la muerte de la muerte.

Con este segundo símil he empezado a poner el énfasis de la consideración en el momento supresivo, que, como acabo de indicar, es esencial e imprescindible en Hegel. Sólo que en el momento final de todo su sistema la supresión ha de afectar a la contradicción misma, cuya solución requiere su eliminación. Hegel estima que si se suprimen los contradictorios mutuos, se elimina también la contradicción. Ahora bien, lo contradictorio, para Hegel, es lo finito ${ }^{87}$, de manera que la supresión de la contradicción no es otra cosa sino la supresión de la finitud. Hegel lo expresa con la frialdad de un pensamiento objetivante: el no ser de lo finito es el ser de lo Absoluto ${ }^{88}$; el hombre, incluso los grandes hombres, son cáscaras vacías de las que se desprende el infinito cuando alcanza su fin ${ }^{89}$; el espíritu finito es el material de la realización del concepto de Dios $^{90}$. Por tanto, la tan prometida y esperada reconciliación de los opuestos consiste no en la convivencia íntima de lo finito y de lo infinito, sino en la supresión y el sacrificio de lo finito en aras de la infinitud absoluta. En el espíritu finito mismo, nos dice Hegel, existe un impulso por el que tiende a anularse a sí mismo, a suprimirse como finito ${ }^{91}$. No podía ser de otra manera.

ten, sondern die reine Negativität selbst. Dieser Punkt ist nämlich wichtig, weil das Göttliche überhaupt als Geist gefaßt werden soll, worin liegt, daß es konkret sein und das Moment der Negativität in sich haben muß... Und dies eben ist das Tiefe, daß im Gott das Negative, der Widerspruch zur Anschauung kommt“ (HW 12, 240). Cfr. 16, 421-22: „Jener Behauptung des Todes im Göttlichen gegenüber steht die Forderung, daß Gott gefaßt werden muß als höchstes Wesen, nur mit sich identisch, und diese Vorstellung wird für die höchste und vornehmste gehalten, so daß der Geist erst zuletzt zu dieser Vorstellung kommt“.

87 HW 5, 139. Las cosas finitas son contradictorias en sí mismas (HW 6, 79). Cada ser y pensar finito es una contradicción (HW 11, 473). La finitud de una existencia descansa en la contradicción (HW 11, 540). „Dieser Tod scheint zunächst etwas Unwürdiges zu sein; wir haben in unserer Vorstellung, daß es das Los des Endlichen ist, zu vergehen, und nach dieser Vorstellung wird der Tod, insofern er von Gott gebraucht wird, nur als Bestimmung aus der Sphäre des ihm unangemessenen Endlichen auf ihn übertragen; Gott wird so nicht wahrhaft gewußt, vielmehr verschlechtert durch die Bestimmung der Negation“ (HW 16, 421). Lo accidental (finito) es la contradicción en sí, lo que ha de ser resuelto (HW 17,482). Las apariencias contradictorias que sirven de base a las antinomias son contenidos finitos (HW 20,356). Lo finito es también lo falso, lo parcial.

88 "Das Nichtsein des Endlichen ist das Sein des Absoluten“ (HW 6, 80). „Das Endliche ist nur wesentliches Moment des Unendlichen; das Unendliche ist die absolute Negativität, d. h. Affirmation, die aber Vermittlung in sich selbst ist" (HW 16, 190-191).

89 "Ist der Zweck erreicht, so fallen sie, die leeren Hülsen des Kernes, ab" (HW 12, 47).

90 „Das Bewußtsein des endlichen Geistes ist das konkrete Sein, das Material der Realisierung des Begriffs Gottes“ (HW 17, 533).

91 „Innerhalb dieser Endlichkeit fällt schon die Aufhebung des Endlichen; jeder Trieb als subjektiv bezieht sich auf Anderes, ist endlich, aber er hebt diese Beziehung, dies Endliche auf, indem er sich befriedigt“" (HW 16,175).El espíritu humano estima lo finito como nada, y con esa 
De la confrontación entre Dios y el hombre no puede resultar otra cosa que la eliminación de este último. En el fondo Hegel no ha ido mucho más allá del anhelo que el joven Schelling ponía en el espíritu de Espinosa: “iAniquílate a ti mismo!... iPiérdete en el infinito!"92. A diferencia del primer Schelling, Hegel sí admite el paso de lo infinito a lo finito (alienación), e igualmente el de lo finito a lo infinito, pero este último paso lleva consigo la total eliminación de la finitud.

A pesar de su titánica lucha contra el empirismo, en el fondo Hegel ha sido vencido por el planteamiento de Ockham. Es verdad que ha rechazado su nominalismo, pero a costa de aceptar el planteamiento más radical de Ockham: la oposición entre Dios y las criaturas, como una oposición entre lo general (absoluto) y lo particular (desechable). En Ockham esa oposición resulta de la introducción de la noción de poder en lo más alto de la divinidad, a través de su interpretación de la omnipotencia como esencia divina, y de las criaturas como seres sin esencia ni poder. En Hegel eso resulta de su interpretación de la naturaleza divina como poder del negativo, y de la finitud como falsedad. Pero el resultado en ambos casos es semejante: la superación de la oposición entre lo finito y lo infinito, entre las criaturas y Dios, ha de conseguirse al precio de la eliminación de lo finito o creado. La contradicción universal hegeliana ya no se mantiene aquí, sino que uno de los contradictorios ha de ser suprimido. Al final, la doble contradicción se resuelve según el principio de contradicción simple: si uno es verdadero, el otro ha de ser falso y, como tal, rechazado.

Si me permiten glosar el texto que propuse como invitación a este congreso y al que también me he referido en su inauguración, se nos cuenta en él cómo Pitágoras celebró una fiesta a la que invitó a todos los habitantes del lugar como muestra de alegría por el descubrimiento de su famoso teorema. El texto es conciso y hermoso, y acaba con una brevísima anotación final: la fiesta se celebró a costa del ganado bovino que sacrificaron. No se trata de ningún adelanto del ecologismo por parte de Hegel, sino del inevitable amargor que acompaña a la alegría hegeliana: toda celebración se ha de hacer a costa de muchos sacrificios, pero la vuelta de Dios a su eternidad conceptual se ha de hacer a costa del sacrificio de todo lo finito ${ }^{93}$. La aniquilación del individuo

negación se eleva, concuerda con Dios; la conclusión "Yo sé que Dios existe" surge por medio de esa negación de sí mismo como finito (HW 17, 528). El espíritu finito es espíritu merced a la doble negación, al poder del negativo, pero es finito en la medida en que es temporal, es decir, en que la forma de dicho poder no es adecuada al mismo. Alcanzar la generalidad es lo que le falta, pero para eso ha de ser eliminado por la negación..

92 Philosophische Briefe über Dogmatismus und Kriticismus, Herausg. von Manfred Schröter, Münchner Jubiläumsdruck, I, 239-240 [315-316].

93 „...der Tod des Natürlichen wird als ein notwendiges Glied im Leben des Absoluten gewußt" (HW 13, 448). 
humano es el precio de la plenitud de Dios. Exactamente al revés de lo que enseña la doctrina cristiana, a saber: que Dios, hecho hombre, sin dejar de ser Dios, sacrificó su vida humana para que los hombres, sin dejar de ser finitos, pudiéramos gozar de su vida eterna. La idea de un Dios que se nutre de sus criaturas no está a la altura de la racionalidad filosófica.

En definitiva, tanto el tiempo como el yo son asociados por Hegel a la formalidad parcial y no verdadera. No son ellos mismos meras formalidades parciales, sino manifestaciones de la pura negatividad, pero sólo en cuanto que ejercida de modo extrínseco o vinculado a la individualidad, es decir, todavía bajo formas falsas o parciales. Nacidos de la alienación de la Idea y vigentes como momentos del proceso de recuperación de la racionalidad, están destinados a desaparecer conjuntamente, absorbidos por el Espíritu Absoluto. El hombre es, por tanto, sólo un medio, un proceso provisional, un tramo del trayecto temporal de recuperación de la formalidad lógica total por el poder del negativo, justamente aquel cuya eliminación total hace advenir ya de modo inmediato al Absoluto. 